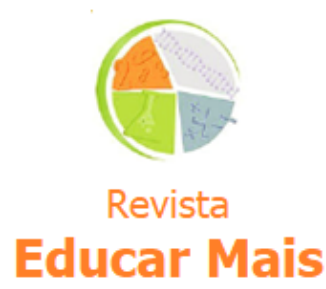

\title{
Opinião dos pais sobre os processos avaliativos nos quais seus filhos são submetidos: Estudo de caso em uma escola de Pelotas
}

\section{Parents opinion about the evaluation processes in which their children are submitted: Case study in a school in Pelotas}

Bruno Gomes da Silva ${ }^{1}$, Giuseppe Bachini ${ }^{1}$; Letícia Soares Nunes Duarte ${ }^{1}$; Marco Antônio Lessa ${ }^{1}$; Cristian Guidotti Aguiar ${ }^{1}$; Marlete de Brum Mackmil ${ }^{1}$; Marcos André Betemps Vaz da Silva ${ }^{1}$

\section{RESUMO}

A passagem do quinto para o sexto ano do ensino fundamental gera alguns traumas na vida escolar dos estudantes. Pois nesta passagem o aluno sofre uma transformação no processo de avaliação de um professor, para vários professores com métodos diferentes de avaliação. 0 objetivo de estudo e descobrir a opinião dos pais de uma escola particular sobre os processos avaliativos nos quais seus filhos são submetidos no quinto ano do ensino fundamental. A metodologia utilizada foi de natureza qualitativa, na qual utilizamos questionários para os pais responderem. A conclusão do estudo foi que, após a integração das unidades de registo nas respectivas categorias, constatou-se das opiniões dos pais ou responsáveis, foi a de que o processo de avaliativo que a escola aplica aos alunos do quinto ano está adequado e preparado para a transição do sistema de currículo para área. Pelo exposto, é importante continuar no aprimoramento do processo avaliativo, pois os pais colocaram alguns aspectos que promovem dados para um aprimoramento do processo.

Palavras-chave: Processos Avaliativos; Ensino Fundamental; Sociedade.

\begin{abstract}
The passage from the fifth to the sixth year of elementary school, generates some traumas in the school life of the students, because in this passage the student undergoes a transformation in the evaluation process of a teacher, for several teachers with different methods of evaluation. The purpose of this study is to discover the opinions of the parents of a private school about the evaluation processes in which their children are submitted in the fifth year of elementary school. The methodology used was qualitative, in which we used questionnaires for parents to answer. The conclusion of the study was that the categories most representative of the opinions of parents or guardians was that the evaluation process of the fifth year is adequate and prepared for the transition from curriculum system to area. Therefore, it is important to continue improving the evaluation process because parents have put some aspects that promote data for a process improvement.
\end{abstract}

Keywords: Evaluation Processes, Fifth year of elementary school, Private School.

\section{INTRODUÇÃO}

Neste trabalho apresentamos um estudo em uma escola particular de ensino situada na cidade de Pelotas, o qual teve como finalidade descobrir a opinião dos pais dos alunos do quinto ano desta escola, sobre os processos avaliativos que seus filhos são submetidos. O processo avaliativo tem como

\footnotetext{
${ }^{1}$ IFSul - Instituto Federal de Educação, Ciência e Tecnologia do Sul-rio-grandense, Pelotas/RS - Brasil.
} 
finalidade para um professor, descobrir o que o aluno sabe, o que não sabe, e a partir disso, construir saberes cognitivos a estes alunos.

O professor deve conduzir este processo de avaliação de uma forma que gere aprendizagem aos estudantes, e não traumas. De acordo com Caldeira (2000) a avaliação escolar é um meio, um processo, e não um final, e precisa ser sustentada por uma prática pedagógica: "Ela não ocorre num vazio conceitual, mas está dimensionada por um modelo teórico de sociedade, de homem, de educação e, consequentemente, de ensino e de aprendizagem, expresso na teoria e na prática pedagógica" (CALDEIRA, 2000, p. 122).

O processo de avaliação é complexo, estamos sempre na mira da avaliação. Isto é inerente das pessoas, $\mathrm{O}$ avaliar faz parte de nosso cotidiano, "seja através das reflexões informais que orientam as frequentes opções do dia-a-dia ou, formalmente, através da reflexão organizada e sistemática que define a tomada de decisões" (DALBEN, 2005, p. 66).

O processo avaliativo além de ser complexo, é único á professor. Para Sordi (2001), "avaliação espelha um juízo de valor, uma dada concepção de mundo e de educação, e por isso vem impregnada de um olhar absolutamente intencional que revela quem é o educador quando interpreta os eventos da cena pedagógica" (SORDI, 2001, p. 173).

Casali (2007, p.10) define o processo de avaliação, "de modo geral, como saber situar cotidianamente, numa certa ordem hierárquica, o valor de algo enquanto meio (mediação) para a realização da vida do(s) sujeitos(s) em questão".

Como podem ver o processo de avaliação e extremamente subjetivo a cada autor, e a cada professor. Os Processos avaliativos na educação se fazem presentes em nossas práticas e na vida de todas as pessoas, pois todos os atos e ações educativas cada vez mais ocupam espaços em nossas preocupações que perpassam o processo de ensino e a aprendizagem consequentemente a avaliação escolar. Nesse sentido Esteban (2001, p.121), "a prática de avaliação fundamentada na lógica classificatória é excludente, ainda que a prática adquira uma aparência inovadora".

A avaliação da aprendizagem escolar não se caracteriza em aprovar ou reprovar o aluno, mas sim orientá-lo permanente para o seu desenvolvimento. Logo o objetivo da avaliação é proporcionar reflexão. Dentro de uma escola também é importante primeiramente conhecer o Projeto Político da escola, para depois pensarmos em avaliação, suporte de nossa prática pedagógica, e, também, o planejamento de ensino, que temos como guia para nossa prática, através do Projeto Político Pedagógico de cada Escola. Como reforça Fernandes (2002):

O projeto pedagógico e a avaliação institucional estão intimamente relacionados. A não existência de um desses processos ou a separação deles trará danos para a própria escola, Sem um projeto pedagógico que delimite a intencionalidade da ação educativa e ofereça horizontes para que a escola possa projetar seu futuro, faltará sempre à referência de todo o trabalho e suas concepções básicas (FERNANDES, 2002, p.58).

O processo avaliativo é complexo e composto por inúmeras situações que interferem em seu andamento. Porém, é de significativa importância e os educadores precisam entender que o processo avaliativo não serve para reprovar os alunos. E sim, para medir o que o educando já entende sobre o conteúdo estudado; medir o quanto o educando aprendeu ao longo do plano pedagógico no qual 
foi submetido; para medir a qual diversidade de culturas e problemas a qual os educandos estão submetidos.

No próximo capítulo desse trabalho, o de metodologia, irá descrever um estudo que investigou a opinião dos pais de alunos sobre os processos avaliativos no qual seus filhos são submetidos.

\section{METODOLOGIA}

O objetivo geral de estudo foi descobrir qual a opinião dos pais de alunos de uma escola particular sobre o processo de avaliação no qual seus filhos são submetidos no quinto ano do ensino fundamental. Para atingirmos estes objetivos, traçamos outros objetivos específicos como: de analisar a formação escolar dos pais dos alunos do quinto ano; averiguar se os pais possuíam tempo livre para acompanhar aos temas destinados a seus filhos realizarem em casa; descobrir se os pais conheciam o Projeto Político Pedagógico da Escola; investigar se os alunos manifestavam alguma posição sobre os processos avaliativos que estavam sendo submetidos.

Este estudo caracteriza-se como uma pesquisa de natureza qualitativa. Uma pesquisa qualitativa tem por natureza de qualificar o sujeito e seus sentimentos. Estudos qualitativos servem para oportunizar a valorização da opinião das pessoas (PELOSO, 2018). Os recursos metodológicos de uma pesquisa qualitativa constroem uma diversidade de opiniões e técnicas que se adaptam a cada caso (PÁDUA, 2016).

\subsection{LOCAL DO ESTUDO}

O estudo foi realizado numa Escola Particular do quinto ano do ensino fundamental, pois a proposta inicial lançada na disciplina de Processos Avaliativos do Mestrado em Ciências e Tecnologias na Educação do Instituto Federal Sul-rio-grandense propôs a investigação numa escola de séries iniciais e no período de transição dos alunos: o Quinto Ano.

Figura 1: Entrada da Escola.

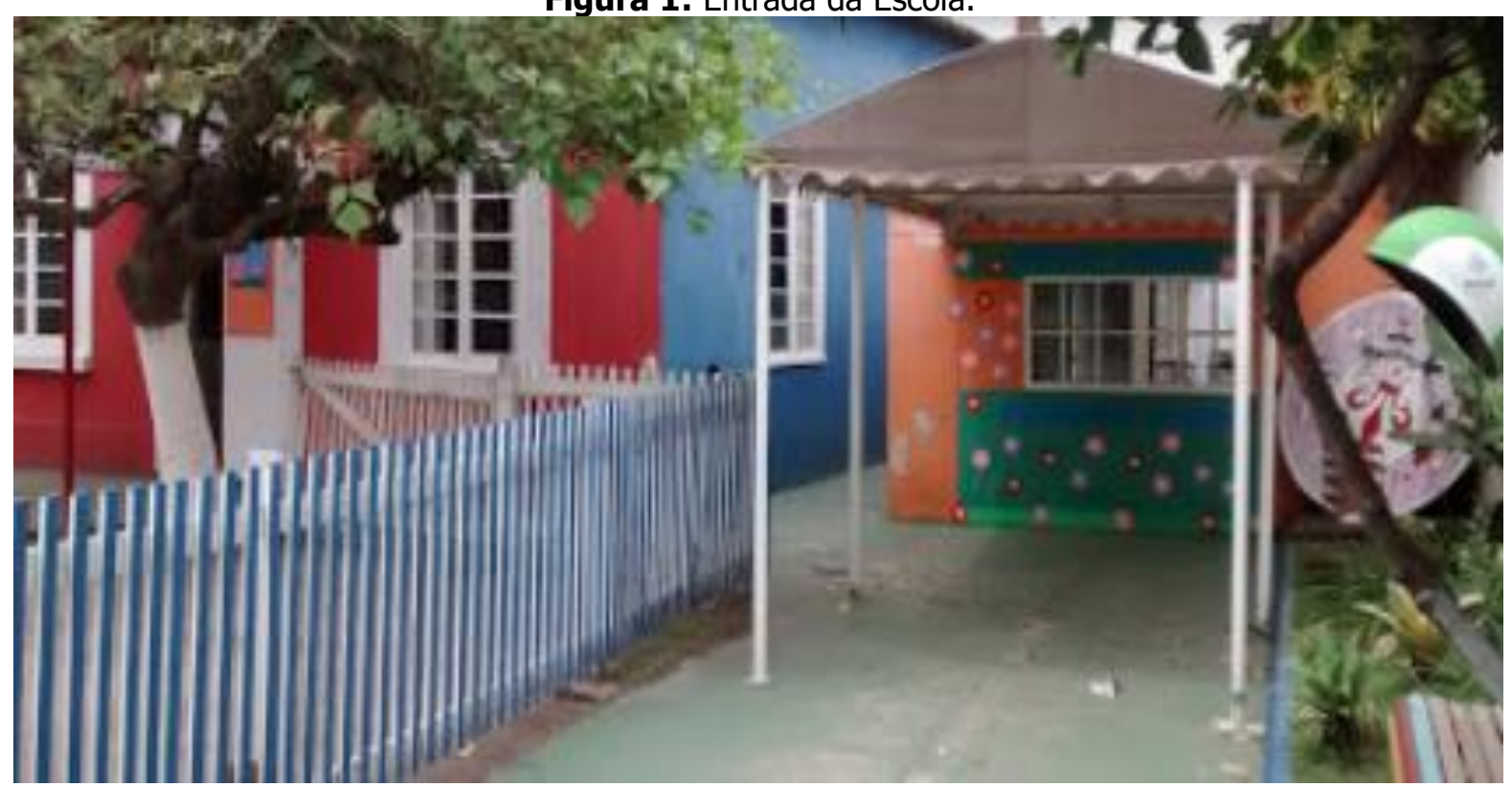

Fonte: autor. 


\subsection{INSTRUMENTO DE COLETA DE DADOS}

O Instrumento de coleta de dados foi entregue aos pais dos alunos do Quinto Ano da escola particular de ensino em Pelotas. Os pais se posicionaram frente aos questionamentos com a finalidade de descobrirem as possíveis divergências que seus filhos são submetidos no processo de avaliação escolar.

O questionário foi composto de questões fechadas e abertas. Com o intuito de investigar a formação escolar dos pais dos alunos do quinto ano; averiguar se os pais possuíam tempo livre para acompanhar aos temas destinados a seus filhos realizarem em casa; descobrir se os pais conheciam o Projeto Político Pedagógico da Escola; investigar se os alunos manifestavam alguma posição sobre os processos avaliativos que estavam sendo submetidos.

Quadro 1: Instrumento de coleta de dados entregue aos pais dos alunos.

\section{Complete ou marque um (x) na opção que traduz a sua situação:}

1.1. Gênero: Feminino ( ) Masculino ( )

1.2. Formação Acadêmica:

( ) primeiro grau

( ) segundo grau

( ) Curso superior

( ) Pós-graduação

b-1. Qual é a área de atuação?

\section{Dados Específicos:}

2.1 Qual o número de filhos que estão estudando nesta escola?

2.2 Qual a idade do estudante que está no quinto ano?

2.3 filho ( ) Filha ( )

2.4 Seu filho(a) já manifestou opinião quanto ao tipo de avaliação a que está submetido?

2.5 Você dispõe de um horário específico para acompanhamento do desempenho de seu filho? Quanto tempo em horas?

2.6 Você conhece o projeto pedagógico da escola? Sim ( ) Não ( ).

2.7 Qual a sua opinião sobre o processo avaliativo desenvolvido pela escola.

2.8 O sistema de avaliação da escola está preparado para troca de currículo para área.

2.9 A escola proporciona um momento de informação sobre o sentimento do aluno?

\subsection{MÉTODO APLICADO}

Consideraram-se como unidade de análise "cada opinião identificada nas respostas" e como unidades de registo as diversas unidades identificadas a partir da unidade de análise definida, ou seja, a partir de uma unidade mínima, unidade de análise pôde ser identificada e codificada todas as opiniões encontradas nas respostas dos participantes no estudo sobre processo avaliativo desenvolvido pela escola.

Dos dados obtidos, fornecidos pelos Pais ou responsáveis, foram definidas as seguintes categorias: Ótimo, Bom, Satisfatório, Insatisfatório, não tem opinião formada. O estudo é de natureza qualitativa, realizado a partir de procedimentos experimentais, pois os dados foram obtidos por questionário, a 
partir das respostas dadas por um conjunto de Pais ou responsáveis de alunos do ensino fundamental incompleto, as questões de resposta semiestruturada. Na análise dos dados seguiu-se uma abordagem descritiva e interpretativa a partir da definição de uma unidade de análise, identificação das unidades de registro, definição de categorias e organização das unidades de registro nessas categorias.

Atendendo aos objetivos do estudo podemos considerá-lo exploratório, pois embora não exista a possibilidade de generalizar os resultados, pois são obtidos a partir de Pais ou responsáveis de alunos de uma única instituição de ensino fundamental incompleto, podem servir como indicadores para orientar futura adequação nos processos avaliativos da escola pesquisada.

De acordo com os procedimentos realizados o estudo assume características de experimental por inquérito, pois foi administrado um inquérito por questionário no mês de novembro de 2018.

Os questionários, foram disponibilizados, aos pais ou responsáveis dos alunos do quinto ano do ensino fundamental e participaram 9 pais ou responsáveis dos alunos do quinto ano que correspondem, aproximadamente, a 40,9\% do total da turma, sendo 33,3\% do gênero masculino e 55,5\% do gênero feminino. Relativamente para formação acadêmica dos pais ou responsáveis. A distribuição apresentase da seguinte forma: ensino fundamental [01] - 11,1\%; ensino médio [02] - 22,2\%; nível superior incompleto [0] - 0,0\%; nível superior completo [05] - 55,5\%; Pós-Graduação [02] - 22,2\%. A distribuição dos pais ou responsáveis pela categoria profissional é a seguinte: Caixa 11,1\%, Mecânico 11,1\%, Pedagogo 11,1\%, Contador 22,2\%, Bancário 11,1\%, Ensino 11,1\%, Assistente Social 11,1\%, Não Informou $11,1 \%$.

Atendendo a que na investigação qualitativa o investigador pode ser considerado o instrumento fundamental de recolha de dados, é importante clarificar que embora possa partir de várias interpretações, deve assumir que depois de definir os conceitos envolvidos e os procedimentos adequados que orientam a investigação, os dados e as conclusões obtidas devem ser facilmente entendíveis, com consistência interna e sem contradições. Neste sentido, se tentará clarificar alguns conceitos associados à investigação qualitativa e de um modo particular à análise de conteúdo, especificamente os conceitos de unidade de análise, unidade de registo e categoria.

De acordo com Moraes (1999), a análise de conteúdo constitui uma metodologia de pesquisa usada para descrever e interpretar o conteúdo de toda a classe de documentos e textos, conduzindo a descrições sistemáticas, qualitativas ou quantitativas, ajudando a interpretar a informação e a compreender os significados a um nível aprofundado.

Ao ter um conjunto de informação é importante obter proveito real dessa informação, dando-lhe sentido, a partir de uma organização onde tenha sentido identificar cada uma das suas partes e agrupá-las de modo a poder distinguir a informação mais representativa do assunto em estudo da menos representativa. Assim, considerando o conjunto de informação em estudo, que pode ser, entre outras, um texto, um livro, um conjunto de respostas a uma questão, ou um conjunto de respostas a um questionário, coloca-se a questão: como se pode medir esta grandeza (conjunto de informação)? Como é usual, para medir uma grandeza seleciona-se uma unidade e em seguida verifica-se quantas vezes "cabe" a unidade escolhida na grandeza a medir, considerando esse número de vezes como a medida da grandeza. 
Moraes (1999), salienta as seguintes etapas no processo da análise de conteúdo: preparação das informações, transformação do conteúdo em unidades, categorização ou classificação das unidades em categorias, descrição e interpretação.

No contexto da análise de conteúdo e considerando um conjunto de informação para análise, designámos como unidade de análise a unidade mínima que permite dividir a totalidade da informação em várias unidades, designando cada uma dessas unidades, identificadas a partir da unidade mínima, por unidade de registo. Após a organização das unidades de registo em classes de acordo com critérios claramente definidos, obtêm-se categorias. Neste sentido, cada categoria é uma classe constituída por um conjunto de unidades de registo com sentido idêntico ou que satisfazem os mesmos critérios de associação.

De acordo com (MORAES; ALVES; MIRANDA, 2013) a unidade de análise é a unidade de significação a codificar e corresponde ao segmento de conteúdo a considerar como unidade de base, visando a categorização, a contagem e a frequência. Ou seja, pode-se considerar como unidade de análise a unidade mínima de informação que permite codificar a informação a analisar num conjunto de outras unidades, cada uma das quais será designada por unidade de registo.

O mesmo autor acrescenta que a categorização é uma operação de classificação de elementos constitutivos de um conjunto por diferenciação e por reagrupamento de acordo com critérios previamente definidos. As categorias são rubricas ou classes que integram as unidades de registo. Estes elementos são agrupados devido ao fato de terem características comuns, procurando apresentar de forma condensada e simplificada o sentido dos dados em bruto.

Para Moraes (1999) a categorização é um procedimento de agrupar dados considerando a parte comum existente entre eles. Classifica-se por semelhança ou analogia, segundo critérios previamente estabelecidos ou definidos no processo.

Após a organização de um conjunto de informação num conjunto de categorias, este deve verificar, pelo menos, duas características essenciais: exclusividade e exaustividade. Exclusividade garante que não existe qualquer unidade de registo que pertença a mais do que uma categoria; exaustividade garante que cada unidade de registo identificada no conjunto de informação foi integrada em alguma categoria.

\section{RESULTADOS E DISCUSSÕES}

A análise de conteúdo é essencial quando se trata de investigações que seguem o paradigma de investigação qualitativa. A investigação qualitativa é por vezes bastante complexa pelo conjunto de dimensões que envolvem, assim como a dificuldade em definir a unidade de análise e em codificar as unidades de registo em coerência com a unidade de análise.

Os resultados sobre o processo avaliativo desenvolvido pela escola, foram obtidos a partir das respostas dadas por pais ou responsáveis dos alunos do quinto ano do ensino fundamental desta escolar.

Assim, os dados foram obtidos a partir da resposta às questões "Qual sua opinião sobre o processo avaliativo desenvolvido pela escola?" e "O sistema de avaliação da escola está preparado para troca de currículo para área?". 
Depois de uma leitura de todas as respostas e de analisar qual seria a unidade de análise que melhor poderia permitir a categorização dos dados obtidos optou-se por considerar como unidade de análise: "cada opinião identificada nas respostas dos sujeitos que participaram no estudo". A utilização da unidade de análise considerada permitiu identificar todas as opiniões manifestadas nas respostas, cada uma das quais foi designada por unidades de registo.

Nem todos os pais ou responsáveis pelos alunos da amostra responderam às questões referida. Dos 22 pais ou responsáveis, 9 responderam (40,9\%).

Considerando que o objetivo principal do estudo foi avaliar a opinião sobre o processo avaliativo desenvolvido pela escola, no conjunto de todas as unidades de registo foram definidas as seguintes categorias: Ótimo, Bom, Satisfatório, Insatisfatório, não tem opinião formada.

Segue-se a definição de cada uma das categorias:

- Ótimo: quando a opinião é favorável sem focar qualquer aspeto específico;

- Bom: quando a opinião é favorável relativamente às características algum aspeto particular;

- Satisfatório: quando a opinião é favorável relativamente às características da avaliação;

- Insatisfatório: opinião é desfavorável relativamente às características da avaliação;

- Não tem opinião formada: não manifestou opinião referente ao sistema de avaliação;

Na Tabela 1 apresenta-se a distribuição das unidades de registo identificadas nas respostas dos pais ou responsáveis pelas respetivas categorias. Pela observação da Tabela I constata-se que as categorias mais representativas, atendendo ao número de unidades de registo que incluem, são Ótimo e Bom, evidenciando que os pais ou responsáveis, valorizam de forma inequívoca o processo avaliativo da escola.

Tabela 1: Opinião dos pais dos alunos do quinto ano sobre o processo avaliativo

\begin{tabular}{|c|c|c|}
\hline Categorias & \multicolumn{2}{|c|}{ Unidades de Registro } \\
\hline & No de unidade & $\%$ \\
\hline Ótimo & 1 & 11,1 \\
\hline Bom & 4 & 44,4 \\
\hline Satisfatório & 2 & 22,2 \\
\hline Insatisfatório & 1 & 11,1 \\
\hline
\end{tabular}

Apresentam-se alguns exemplos de unidades de registo integradas nas respetivas categorias, das opiniões dos pais ou responsáveis sobre o sistema avaliativo da escola:

- Ótimo: "Acho ótimo".

- Bom: "Bom, segue os livros exposto pela escola" / "Bom, pois acostuma o aluno com avaliações, sem ser muito agressivo" / "Gosto muito de todo o processo da escola, mas o acúmulo de provas em uma semana é desgastante!" / "Está ajudando bastante no desempenho dos alunos" 
- Satisfatório: Satisfatório.

- Insatisfatório: "Acho que demorou muito para que as crianças fizessem provas sem consulta".

- Não tem opinião formada: Não tenho opinião.

Em síntese, em termos do processo avaliativo os pais ou responsáveis, na maioria, consideram que o mesmo aplicado pela escola está de acordo com suas expectativas.

Na Tabela 2 apresenta-se a distribuição das unidades de registo identificadas nas respostas dos pais ou responsáveis no que diz respeito a troca de currículo para área pelas respetivas categorias.

Tabela 2: O sistema de avaliação da escola está preparado para troca de currículo para área?

\begin{tabular}{|c|c|c|}
\hline Categorias & \multicolumn{2}{|c|}{ Unidades de Registro } \\
\hline & No de unidade & $\%$ \\
\hline Sim, concorda & 6 & 66,6 \\
\hline Não concorda & 1 & 11,1 \\
\hline Não sabe & 1 & 11,1 \\
\hline Não respondeu & 1 & 11,1 \\
\hline
\end{tabular}

Pela observação da Tabela 2 como aconteceu na questão anterior, listamos as categorias representativas são: sim, concorda; não concorda; Não sabe; Não tem opinião formada.

Figura 5: Representativos da tabela 1 e 2.

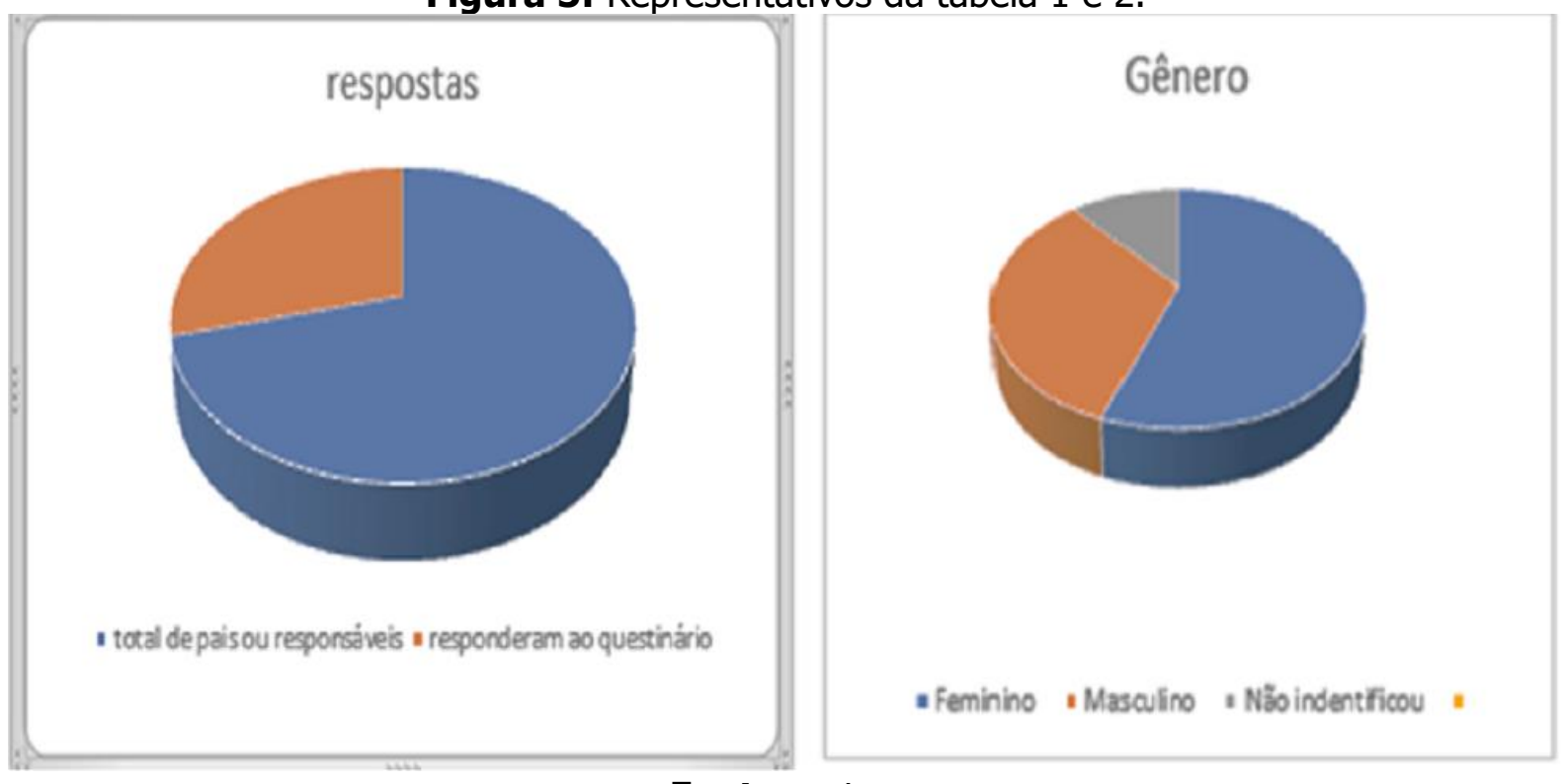

Fonte: autor.

Apresentam-se alguns exemplos de unidades de registo integradas nas respetivas categorias:

- Sim, concorda: "Este ano sim "/ "acredito que sim "/ " sim "/ "acredito que sim".

- Não concorda: "Esta em construção."

- Não Sabe: "Esta certeza vamos ter quando for para outra escola".

- Não respondeu 
Em síntese, em termos de preparação de troca de currículo para área a maioria dos pais considera que o sistema de avaliação está adequado para a transição que se aproxima.

Tabela 3: Gênero dos Pais ou Responsáveis

\begin{tabular}{|c|c|c|}
\hline Categorias & \multicolumn{2}{|c|}{ Unidades de Registro } \\
\hline & No de unidade & $\%$ \\
\hline Feminino & 5 & 55,5 \\
\hline Masculino & 3 & 33,3 \\
\hline Não identificou & 1 & 11,1 \\
\hline
\end{tabular}

Dois pais possuem cursos de pós-graduação, cinco dos pais contemplam cursos de ensino superior e dois de ensino médio.

Tabela 4: Formações Acadêmicas dos Pais ou responsáveis.

\begin{tabular}{|c|c|c|}
\hline Categorias & \multicolumn{2}{|c|}{ Unidades de Registro } \\
\hline $\begin{array}{c}\text { Ensino } \\
\text { Fundamental }\end{array}$ & 1 & de unidade \\
\hline Ensino Médio & 2 & 22,2 \\
\hline $\begin{array}{c}\text { Nível Superior } \\
\text { Incompleto }\end{array}$ & 0 & 0,0 \\
\hline $\begin{array}{c}\text { Nível Superior } \\
\text { completo }\end{array}$ & 5 & 55,5 \\
\hline $\begin{array}{c}\text { Nível Pós- } \\
\text { Graduação }\end{array}$ & 1 & 11,1 \\
\hline
\end{tabular}

Tabela 5: Área de atuação dos Pais ou responsáveis

\begin{tabular}{|c|c|c|}
\hline Categorias & \multicolumn{2}{|c|}{ Unidades de Registro } \\
\hline & $\mathbf{N}^{0}$ de unidade & $\%$ \\
\hline Informática/Pedagogia & 1 & 11,1 \\
\hline Mecânica & 1 & 11,1 \\
\hline Caixa & 1 & 11,1 \\
\hline Contador & 2 & 22,2 \\
\hline Bancário & 1 & 11,1 \\
\hline Ensino & 1 & 11,1 \\
\hline Assistente Social & 1 & 11,1 \\
\hline Não informado & 1 & 11,1 \\
\hline
\end{tabular}


Figura 6: Área de atuação e formação dos Pais.

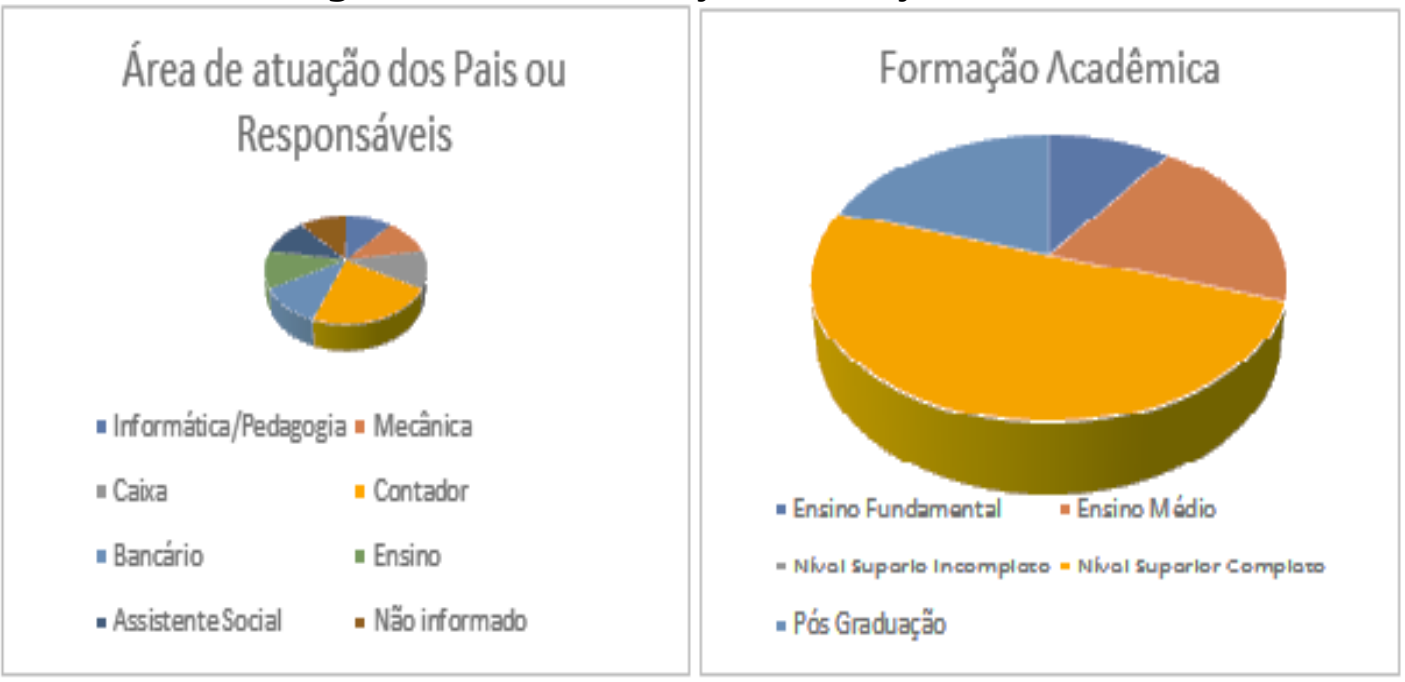

Fonte: autor.

Tabela 6: Número de filhos na escola

\begin{tabular}{|c|c|c|}
\hline Categorias & \multicolumn{2}{|c|}{ Unidades de Registro } \\
\hline & No de unidade & $\%$ \\
\hline Único filho & 8 & 88,8 \\
\hline Dois filhos & 1 & 11,1 \\
\hline
\end{tabular}

A maioria dos pais tem apenas um filho na escola. E 66,6\% dos educandos do Quinto Ano possuem média de Dez anos de idade.

Na sequência, entramos na discussão sobre os processos de avaliação aos quais os estudantes estão sendo inseridos. Na questão "Seu filho (a) já manifestou opinião quanto ao tipo de avaliação a que está submetido?" percebemos que $66,6 \%$ dos pais informaram que não houve qualquer tipo de manifestação das crianças e apenas 33,3\% realizaram algum tipo de comentário sobre o tipo de avaliação na escola. Nesta mesma perspectiva de análise, questionamos com relação ao tempo que os pais dispõem para acompanhamento do desempenho do seu filho, ou seja, se dedicam algum tempo para desenvolver atividades de casa com os filhos e automaticamente verificar como esta sendo seu aprendizado. Percebeu-se que aproximadamente $45 \%$ dos pais dedicam aproximadamente 1 hora para estas atividades, enquanto outros $55 \%$ dedicam mais de 1 hora para o acompanhamento.

A partir deste ponto passamos a analisar o conhecimento dos pais com relação ao projeto pedagógico da escola, onde, por consequência vão estar descritos questões relativas também à avaliação. Neste ponto, $18 \%$ dos pais declararam não conhecer o projeto pedagógico da escola, $72 \%$ disseram conhecer o projeto pedagógico, e $10 \%$ não respondeu. Porém quando questionados sobre 0 que dizia o Projeto Político Pedagógico da escola, não apresentaram explicações que indicassem o conhecimento de tal documento.

O próximo questionamento apresentado aos pais questiona se a escola proporciona algum tipo de momento para possibilitar o aluno a apresentar suas percepções com relação à escola. $78 \%$ dos pais relataram que sim. Esse momento é denominado de conselho de classe, dos quais a grande maioria dos entrevistados respondeu que não costumam frequentar. Este fato pode indicar que a participação dos pais no acompanhamento da vida estudantil pode até ocorrer de maneira efetiva, entretanto, não tem se efetivado nos espaços que a Escola proporciona. 


\section{CONCLUSÃO}

Esse trabalho possuiu como objetivo de descobrir qual a opinião dos pais de alunos de uma escola particular sobre o processo de avaliação no qual seus filhos são submetidos no quinto ano do ensino fundamental. Para atingir este objetivo foram traçados outros objetivos espeć́ficos como de analisar a formação escolar dos pais dos alunos do quinto ano; averiguar se os pais possuíam tempo livre para acompanhar aos temas destinados a seus filhos realizarem em casa; descobrir se os pais conheciam o Projeto Político Pedagógico da Escola; investigar se os alunos manifestavam alguma posição sobre os processos avaliativos que estavam sendo submetidos.

O estudo seguiu uma abordagem qualitativa, cujos dados foram obtidos por questionário a partir de questões de resposta semiestruturadas. No estudo participaram 9 pais ou responsáveis de alunos do quinto ano da escola particular de ensino de pelotas. $\mathrm{Na}$ análise das respostas foi considerada como unidade de análise "cada opinião identificada nas respostas dos sujeitos que participaram no estudo".

Em função da unidade de análise definida foram identificadas 9 unidades de registo nas respostas dos pais ou responsáveis. As unidades de registo foram integradas nas categorias: Ótimo, Bom, Satisfatório, Insatisfatório, Não tem opinião formada. Sim, concorda; não concorda; Não sabe; Não tem opinião formada.

Após a integração das unidades de registo nas respetivas categorias constatou-se que as opiniões dos pais ou responsáveis, foi que o processo avaliativo que a escola particular de ensino de Pelotas aplica aos alunos do Quinto Ano está adequado e preparado para a transição do sistema de currículo para área.

Desse modo fica registrada a importância dos processos avaliativos. Bem como, dos professores olharem com carinho a esta etapa, pois este mede um momento de reflexão, para que os professores possam melhorar o processo de ensino e aprendizagem. Esse, não é um momento apenas de reprovar e aprovar, o processo avaliativo é um momento de reflexão para o professor entender como esta o andamento de suas aulas, se os estudantes estão de fato aprendendo e evoluindo.

\section{REFERÊNCIAS}

CALDEIRA, Anna M. Salgueiro. Resinificando a avaliação escolar. Comissão Permanente de Avaliação Institucional: UFMG-PAIUB. Belo Horizonte: PROGRAD/UFMG. p. 122-129 (Cadernos de Avaliação, 3). 2000.

CASALI, A. Fundamentos para uma avaliação educativa. In: CAPPELLETTI, I. F. Avaliação da aprendizagem: discussão de caminhos. São Paulo: Editora Articulação Universidade/Escola, 2007.

DALBEN, Ângela I. L. de Freitas. Avaliação escolar. Presença Pedagógica, Belo Horizonte, v. 11, n. 64, jul./ago. 2005.

ESTEBAN, Maria Tereza. O Que sabe quem erra? Reflexões sobre a avaliação e fracasso escolar. Rio de Janeiro: DP\&A, 2001.

FERNANDES, M. E. A. Avaliação institucional da escola e do sistema educacional: base teórica e con do projeto. Fortaleza: Edições Demócrito Rocha, 2002. 
MORAES, C., ALVES, P., \& MIRANDA, L. Valorização dos ambientes virtuais de aprendizagem por professores do ensino superior. In A. Rocha, L. Reis, M. Cota, M. Painho, M. Neto (eds.). Sistemas e Tecnologias de Informação. Atas da $8^{a}$ Conferência Ibérica de Sistemas e Tecnologias de Informação. Vol. I, (p. 289- 294). Associação Ibérica de Sistemas e Tecnologias de Informação. Lisboa, 2013.

MORAES, R. Análise de conteúdo. Revista Educação, Porto Alegre, 22(37), 7-32. 1999.

PELOSO, M. J. et al. Investigação Qualitativa: para melhor entendimento das transformações na complexidade humana. Revista Anhanguera: Pesquisa Qualitativa. Centro Universitário de Goiás, n.1. janeiro. Goiânia, 2018.

SORDI, Mara Regina L. de. Alternativas propositivas no campo da avaliação: por que não? In: CASTANHO, Sérgio; CASTANHO, Maria Eugênia (orgs.). Temas e textos em metodologia do Ensino Superior. Campinas, SP: Papirus, 2001. 